\title{
Student Perspectives on Study Skills in a Turkish State Secondary School Sample from Adana
}

\author{
M. Oğuz Kutlu ${ }^{1} \&$ Şadiye Korkmaz ${ }^{1, *}$ \\ ${ }^{1}$ Çukurova University, Adana, Turkey \\ ${ }^{2}$ Ahmet Sapmaz Secondary School, Ministry of Education, Adana, Turkey \\ *Corresponding author: Education Faculty, Çukurova University, Turkey. Tel: 90-322-338-6434. E-mail: \\ okutlu@cu.edu.tr
}

$\begin{array}{ll}\text { Received: September 16, } 2013 & \text { Accepted: October 27, 2013 Online Published: November 20, } 2013 \\ \text { doi:10.5430/wje.v3n6p15 } & \text { URL: http://dx.doi.org/10.5430/wje.v3n6p15 }\end{array}$

\begin{abstract}
The primary aim of this study was to examine the preferences of 8th grade students who had high academic grades in several study skills categories. The study group consisted of 23 8th grade students who were attending a state secondary school in the province of Adana, Turkey, during the 2012-2013 academic year. The research method was qualitative. Content analysis and descriptive analysis were used to analyse the data. The data were collected through semi-structured interviews with interview forms. All of the interviews were audio-recorded, learners gave written consent to participate and consented orally to the interview and audio recording. The audio recordings were transcribed. As a consequence of this research, the learners clarified their views about the study skills categories. Most of the learners expressed the following preferences: 12 students stated that they prepared study plans and weekly schedules; 14 students emphasised that they divided their courses into smaller content units when they reviewed the course material; 15 learners stated that their study environment must be quiet; 7 students stated that they listened to music when experiencing stress; 9 students believed that stress is necessary for learning and determined that it should be maintained at an appropriate level; 4 students said that they increased their motivation by reviewing the course material; and 3 students explained that studying effectively increases their motivation. In conclusion, when the study skills categories discussed in the literature are used to analyse students' study habits, students seem to apply the categories of study skills when studying their course material.
\end{abstract}

Keywords: study skills; learning; effective learning; learning styles; learning strategies

\section{Introduction}

Luckie and Smethurst (1998) indicated that academic success largely depends on an individual's ability to organise their academic work and their time effectively and in a conscious manner. Though success also depends on a student's talent and enthusiasm, organisation ability, rather than intelligence, speed, greed, or other characteristics, has the most influence on a student's success. A student desiring to know how to study a course will identify a key to understand the topic described in the course and solve the problem or issue he or she confronts. When the learner solves the problem, a successful conclusion is reached and a feeling of accomplishment follows. Learners are crucial in the learning process and are responsible for their own learning process. In the early twentieth century, education was based on a learning theory that is called behaviourism. According to this theory, the learner was a passive recipient whose mind was subjective. This theory's definition of the mind was clear and concise, it suggested that the concept of the mind should be avoided by scientists to maintain objectivity (Philips \& Soltis, 1991). However, in contemporary learning theories, the learner in the academic environment is both active and responsible for his or her own learning. Students obtain success during the learning process through their own efforts. Researchers have long studied knowledge acquisition and have found that learning is affected by many factors. Individuals who receive knowledge are important in the learning process (Açıkgöz, 2005). Contemporary theories of teaching and learning reveal that students should take a more active role in the learning process, but their ability to do this is dependent on their study skills and learning methods. Study skills include planning, which encompasses tactics, strategies and manoeuvres (Schmeck, 1998). Strategies and tactics are developed by learners consciously and deliberately. They are 
within the scope of skills that can be applied through conscious decision (Schmeck, 1998). Study skills categories and learning process affects each other. Behavioural theory is one of the most effective theories that affect learning environment and process. Behaviourists defend reinforcement learning with the help of individual's response to stimuli applied in learning environment, the teacher gives information while the learner takes the information presented to them. However, Piaget, one of the psychologist from Gestalt school and representatives of cognitive theory emphasizes that school should allow learner to guide their own efforts by themselves rather than by the pressure from the outside (Senemoğlu, 2005). Also, Gagne implies that learning is a process, which depends on the configuration of external stimuli with cognitive processes. Learning depends on the interaction of internal factors such as, teaching materials and reviews. Hence, defining the characteristics of emotional interest in cognitive strategies such as, expectations, attitudes and values are important factors. For this reason, Gagne's approach can be appreciated and considered as the synthesis of cognitive learning theories (Driscoll, 2005). Cognitive information processing theory explains that information or stimulus is transferred to working memory through repetition and this repeated information is coded into working memory rather than transmitted to long-term memory storing knowledge as a result of learning. Selective attention is crucial in the beginning of cognitive information process. Selective attention refers to the learner's ability to select and process certain information and also it refers to the learner's ability to ignore other information (Driscoll, 2005).

The constructivist theory and constructionist's view does not accept that the mind is an empty box. Constructivist believes that an individual only experience interaction with the environment and construe the new situation according to his/her experiences. Individuals internalize the information by themselves; new knowledge is built on pre-structured information. John Dewey defends that learners initialize the information with their own self control and responsibility in accordance with the constructivist theory (1902; Trans. Fosnot, 2005). Robinson (1993) emphasize learning is the dynamic process by which learners take control and become the pilot in their own learning responsibility.

Schools should assist students to learning cognitive development; this kind of awareness is a key for study skills and is responsible for the learner's development (Jung et al., 1971; Biggs et al., 1986, Trans. Schmeck, 1988). Study skills are also related to learners' capacity, motivation and planning and also related to accepting their own cognitive and metacognitive capacities.

\subsection{Study Skills}

Skills are things we can do while strategies and tactics are decisions to apply the things we can do. Also, plans include strategy and tactics. Biggs et al., 1986 unanimously agreed on the issue that skill is combined with the plans, tactics, strategies and manoeuvres. In addition Kirby notes that skills are capacities, or abilities, which can be expressed in behaviour at any time because they have been developed through practice (Schmeck, 1988). Skills refer to the collection of learning and thinking strategies that learners have for tackling various academic tasks. Cognition, motivation, skill and will are important components for academic success and learning (VanderStoep \& Pintrich, 2003). Learners who have high grade review their orginal notes which are about the courses, reconstruct their summary from their memory, make plan, manage their time and balance between routine and flexibility, prepare daily plan or a calendar of the semester are necessary (Robinson, 1993). Study skills categories and learning process affects each other. Study skills include effective learning, efficient studying, time management, motivation, studying, planning, reviewing, choosing a study space and managing stress (Kutlu \& Canbolat Bozkurt, 2007). Students confront many problems when studying and learning. They are expected to learn all of the information that is presented during class time, but they are never taught how to learn. They may study very hard and be highly motivated to succeed. They may spend a lot of time for studying their courses and also they may have a strong desire to be successful however they need study skills for academic success. Study skills are the keys to academic success and study skill is also important for learning to learn (VanderStoep \& Pintrich, 2003). Study skills encompass both academic and personal skills. Academic skills include successful studying. Personal skills include willingness, determination, a positive attitude towards learning, planning abilities and engagement in extra curricular activities (Ekmekçi, 1994). VanderStoep and Pintrich (2003) emphasize study skills include cognitive components and motivational components. Cognitive components comprise rehearsal, elaboration, organization, critical thinking and metacognition. Rehearsal is the cognitive activity of repeating facts or definitions. Elaboration is the process by which the students may achieve sophisticated understanding. Organization includes making charts or outlines of class notes, lecture materials and selecting the most important points from students' textbooks or lecture notes. Critical thinking is the ability to use the knowledge students have acquired in flexible and meaningful ways and metacognition is the awareness and control students have over their own cognition. Motivational components comprise intrinsic motivation, extrinsic motivation, task value, control beliefs, self-efficacy, test anxiety, time management and study environment, effort regulation (determination), peer (group) learning, help seeking. Even students who want to learn and who are eager to succeed in college do not always know successful study techniques or may not have different study techniques for different 
subjects (Mundsack, Deese \& Deese, 2003). It is important for students to become aware of their personal learning preferences and to allow these preferences to inform their studying (Cottrell, 2003). Learners should know how to learn, how to motivate themselves and how to control and self-direct their learning. If students do not know how to learn independently, they may fail (Açikgöz, 2005). Schmeck (1998) stated that contemporary theories related to teaching and learning reveal that students should take a more active role in the learning process, however their ability to do this is dependent on their study skills and learning methods. Study skills include planning, which encompasses tactics, strategies and manoeuvres Strategies and tactics are developed by learners consciously and deliberately. They are within the scope of the skills that can be applied through conscious decision.

Pauk (1984) stressed the most important constituents that cover study skills such as goal setting, motivation, using time schedule, note taking strategies, breathing techniques (Ekmekçi, 1994). Everything starts with values that include beliefs and principles. Long-term goals, principles and beliefs developed in the long-term success. Medium-term goals respectively involved in a number of long-term goals and medium-term targets involve daily targets (Pauk, 2001).

When the constituents are explained, cultural factors may affect students' motivation. Class factors can affect student motivation. Between the socio-cultural beliefs and feelings that caused the student's motivation can be effective in classroom experiences and also general observable behaviours may be indicative of the motivation (Pauk, 1984 and Trans. Ekmekçi, 1994). Managing stress is crucial for study. Excessive stress can blunt learners' memory, however a modest amount of stress may increase their ability to focus and sustain attention and acquire information more effectively (Nelson \& Gilbert, 2005; Wong, 2006). Students should use their time effectively for doing homework and preparing for exams. Students need study skills, a good place to study and plan to regulate and assess their study; study time and free time for take a good mark (Pauk, 2001). A time schedule is a plan that explains and presents what the learner hope to accomplish for a day, a week, or a month also it includes activities which learner enjoys. Pauk (2001) emphasizes that a schedule provides control, encourages relaxation, saves time and increases flexibility. Learner who use time schedule, they provide more free time for a variety of activities. Learners should set realistic schedule and follow the plan and learners should accomplish their study in reasonable amount of time. In addition learners should break up long-term units into reasonable units. They should use review their knowledge (Frender, 2003).

The other most important thing is note-taking, what we read and hear; they become more permanent when we take note. In addition, students should use breathing techniques as Pauk (2001) explained. These techniques are useful for learners, may help some relax (Pauk, 2001).

Erden and Altun (2006) expresses those environmental factors that affect students learning and study conditions as follows:

Body posture: sitting down is a form of study posture that best suits learner. Audio: Studying in a quiet environment is recommended, however, some children have different preferences for voice; low-level music is determined suitable for the relief of nervous systems. Light: fluorescent and bright light disturbs some individuals when studying while medium level light strengthens, reliefs and promote better performance of individual learning (Willis \& Hodson, 1999, Trans. Erden \& Altun, 2006). Interaction: Individuals learn better by interacting with each other. Colour: Study and learning environments with favourite colour can be useful. Heat: Students should study at a suitable temperature. Time: The most suitable time to study is in the morning. Food: Learner should not be hungry before beginning study. Eating before class can deploy attention.

Few studies in the literature have investigated study skills. The problem of the study is "Do the students who have high academic grades apply the study skills described in the literature when they study their lessons?" The purpose of this study is to contribute to the field's knowledge of students' study skills. This research is expected to be useful and beneficial for improving study skills of the learners. It is thought that the most important factor related with difficulties in academic achievement of learners is that they cannot use and apply study skills category or they do not apply these skills directly. Because of all this important items, this research will be expected to affect positively students' academic achievement in the process of learning and teaching activities.

\section{Method}

Qualitative research uses neither random selection nor large groups because its aim is not to produce generalizable results (Glesne, 2011). A reachable sampling method was used to recruit study participants. Participants comprised 23 volunteer 8th grade students who had high academic grades, enrolled in school in Adana, Turkey, during the 
2012-2013 academic year. Qualitative researchers do not use definitions made before relating with how people think and react. Qualitative researchers aim to understand the participants' point of views. One of the reasons is to find out useful generalizations. However, generalization cannot be made in qualitative research studies because of the nature of social phenomena are considered as a limitation. Generalization that is related with the social event is not made for social events as same generalization. It is very difficult to generalize the findings to other social events and not always possible to determine the sample size for representative of the universe in qualitative research study (Fraenkel \& Wallen, 2006; Yıldırım \& Şimsek, 2005). Qualitative approaches emphasize certain common features that were shared (Büyüköztürk et al., 2008). Fraenkel and Wallen (2006) describe that resarchers made qualitative study research to examine relations, events, circumstances or the nature of the materials. Qualitative research methods provide in-depth information. Qualitative and quantitative researches have their own advantages and disadvantages; they have their own strengths and weaknesses. It is important to choose the right method or methods (Fraenkel \& Devers, 2000). Qualitative research offers opportunities for conducting exploratory and descriptive research that uses the context and search for a deeper understanding of the participant or participants in a qualitative research study (Marshall \& Rossman, 1999; Trans. Best, \& Kahn, 2006). A reachable sampling method was used to recruit study participants. Participants comprised 23 volunteer 8 th grade students who had high academic grades, enrolled in school with medium (avarage) socio-economic level in Adana, Turkey, during the 2012-2013 academic year.

\subsection{Study Group}

Table 1: Demographic Characteristics of the Study Group

\begin{tabular}{cccc}
\hline Student Code & Gender & Age & Class \\
\hline S1 & M & 13 & 8 \\
S2 & F & 14 & 8 \\
S3 & F & 14 & 8 \\
S4 & M & 14 & 8 \\
S5 & F & 14 & 8 \\
S6 & F & 14 & 8 \\
S7 & F & 14 & 8 \\
S8 & F & 14 & 8 \\
S9 & M & 14 & 8 \\
S10 & M & 14 & 8 \\
S11 & M & 14 & 8 \\
S12 & M & 15 & 8 \\
S13 & M & 14 & 8 \\
S14 & M & 14 & 8 \\
S15 & F & 14 & 8 \\
S16 & F & 14 & 8 \\
S17 & M & 14 & 8 \\
S18 & M & 14 & 8 \\
S19 & M & 14 & 8 \\
S20 & F & 14 & 8 \\
S21 & F & 14 & 8 \\
S22 & F & 14 & 8 \\
S23 & F & 14 & \\
\hline & & & 8 \\
\hline
\end{tabular}

The learners' demographic data are presented in Table 1. The study group consisted of 238 th grade students pursuing their education in a state secondary school during the 2012-2013 academic year. There were 11 male and 12 female participants. 21 of the students were 14 years old, 1 student was 13, and the remaining student was 15 years old. 


\subsection{Sample Size}

Rich-information situations, validity, significance and perceptions related with researchers' analytical capacities are more important in qualitative research than the sample size (Büyüköztürk et al., 2008). Patton (1990) states that the rule is to decide the sample size for qualitative research. According to Patton sample size: (a) what do you want to know (b) the purpose of study (c) what is useful and beneficial (d) what is valuable and important for the research (e) it depends on what can be done with available time and resources. The ideal sample is large enough to serve as an adequate representation of the population, which the researcher intends to generalize and also, small enough to be selected economically in terms of the subject availability and expense in both time and money. There is no fixed number or percentage of subjects that determines the size of an adequte sample. It may depend on the nature of the population of interest or the data to be gathered and analyzed. A reachable and purposeful sampling method was used in this qualitative research. Participants comprised $238^{\text {th }}$ grade students who had high academic grades, enrolled in school in Adana, Turkey, during the 2012-2013 academic year. Purposeful sampling is often preferred in qualitative research studies. Purposeful sampling allows the researcher to select those participants who will provide the richest information, those who are the most interesting, and who manifest the characteristics of most interest.

\subsection{Data Collection Tool}

The data were collected through semi-structured interviews (Bogdan \& Biklen, 1992; Trans. Cohen, Manion \& Marrison, 2007) conducted and prepared by the researchers. The interview questions were prepared in accordance with the guidelines suggested in the relevant literature. Before being used in the study, the questions were reviewed by experts to determine their legibility, clarity and consistency. The final version of the form was a result of the criticisms and suggestions made during the review process. The interviews consisted of 6 questions with sub-questions soliciting students' perspectives about study skills and were used in a semi-structured interview format. The students were interviewed personally by the researchers, and the interviews were audio-recorded. The interviews took 3 weeks (21 days) to complete. Before the interview, written permission was obtained from the students. After completing the consent form, the students gave oral consent, which was recorded by the researchers after the interview. Transcripts were made from the audio-recordings. One of the most distinctive features of qualitative research is the continuation of research focusing on the event, behaviour and cases occurring in the natural environment. Researchers do not manipulate behaviours or behaviours that occur and they do not make an intervention from the outside. Natural environments can be a class, school, clinic, or it can be a district or neighbourhood. For this reason, qualitative research is often defined as a field research. There are two main reasons for the realization of the field of qualitative research. First, the behaviour occurs without external intervention and controls the best way to understand. Secondly, it is very important to understand the situational context. Behaviour without considering the characteristics of the situation, facts and events cannot be understood. Therefore, qualitative researchers collect data

directly from the relevant environment. Researchers can use notepads and pens; they can also use audio and video recording devices in the research environment (Büyüköztürk et al., 2008). The audio transcripts were examined and studied by two researchers in this study. Thus the internal validity of the research was strengthened. Qualitative research uses different forms of data from those used in traditional research methods. As Patton (1990) sets forth: Qualitative methods consists of three kinds of data collection: (1) interviews, (2) direct observation, and (3) written documents. The data from interviews consist of direct quotations from people about their experiences, opinions, feelings, and knowledge. Document analysis in qualitative inquiry yields excerpts, quotations, or entire passages from organizational clinical or program records; memoranda and correspondence; official publications and reports; personal diaries; and open-ended written responses to questionnaires and surveys (Best \& Kahn, 2006). Interview technique commonly used by qualitative researchers (Fraenkel \& Wallen, 1993) was used in the qualitative research. Fetterman (1988) describes interviewing as the most important data collection technique used by a qualitative researcher. As Frankel and Wallen (1993) remarked: the purpose of interviewing people is to find out what is on their mind; what they think or how they feel about something. Patton identified six basic types of questions that can be asked. The six types are: (1. Background or demographic questions; (2. Knowledge questions; (3. Experience or behaviour questions; (4. Opinion or value question; (5. feelings questions; and (6. sensory questions (Fraenkel and Wallen, 1993). Experience or behaviour questions, opinion or value questions and feelings questions were used as interview questions in this qualitative research study. Before used, experts determine their legibility, clarity and also reviewed the questions consistency. The Experts' fields are Turkish Language and Literature, Mathematics, Social Science and Guidance and Counselling. 


\subsection{Data Analysis}

Content, inductive and descriptive analysis techniques were used to analyse the data. Inductive analysis involves coding the data to reveal the relationships between the concepts by categorising and identifying the significant conceptual groupings (Yıldırım \& Şimşek, 2008). First, the transcripts of the audio-recordings were read several times by the researchers. Second, the common answers were identified. Following Strauss and Corbin's (1998) suggestion, the code list was prepared separately according to pre-determined concepts. Finally, the common themes and categories were constituted, interpreted and assigned codes by the researchers. The themes, codes and subthemes are supported by examples of student responses in the tables. Interview notes, field notes, photographs, audio recordings, video recordings, diaries, personal comments, office records and short notes can be obtained from different data in Qualitative research. It is considered that each detail record provides better understanding of the behaviour. Simple numerical numbers can be used for summary in qualitative research; however, descriptions are made with a lot of words and pictures in qualitative studies. Hypotheses are not specified as precise and clear. In conclusion these data are synthesized by means of induction to make generalizations. Analyzing the data in a qualitative study essentially involves synthesizing the information obtained from various sources (such as observations, interviews, document analysis) into a coherent description of what is observed and discovered. Data analysis in qualitative research relies heavily on description; even when certain statistics are calculated, the qualitative research tends to be used in a descriptive rather than an infrential sense (Fraenkel \& Wallen, 2006). Descriptive statistical analysis limits generalization to the particular group of individuals observed. Conclusions are not extended beyond this study group, and any similarity to the other group(s) cannot be assumed. The data describe only one study group, however, descriptive analysis provides valuable information about the nature of a particular group of individuals. Therefore, Descriptive statistical analysis was used in this qualitative study.

\subsection{Validity and Reliability}

Validity describes the correctness of scientific findings in qualitative research. Reliability is the reproducibility of scientific findings in qualitative research (Yıldırım \& Şimşek, 2008). To increase the validity and reliability of this research, the relevant literature was reviewed and a conceptual framework was developed. The integrity of the content analysis was confirmed by verifying the relationship between the emerging themes and the theme categories. In addition, to enhance the validity of the research, the research process and the structures that were established by this process were explained in detail. The research model, the study group, the data collection tool and the data analysis and interpretation methods were therefore elaborated in detail. To increase the reliability of the study, all of the findings were presented directly.

Reliability in qualitative research data to record everything that occurred in the study research environment. The (qualitative) researchers need to provide accurate and comprehensive information. They kept audio records, video records and images, participants' citations and quotations for increasing reliability. The researchers registered the data used in this research. This case provided information on the reliability of the results. Researchers determined and prepared the results theme and sub-included themes according to obtained comments as written in the form of audio recording without changing the voice records (Büyüköztürk et al., 2008). The generalizability of the results depends on the external validity of certain cases, the purpose is to provide in-depth understanding of certain cases in qualitative research, since a qualitative research does not represent a broad sample, selected method is specified for this study thus resulting into reason low generalizability. Comparability and recyclability concepts used are related with external validity in qualitative research. Therefore, a qualitative survey data, the main themes and sub-themes analyzed each of the stages and how well defined the cases make things easier for other researchers to understand the results of similar studies in other studies, and patterns (Büyüköztürk et al., 2008).

\section{Results}

The Study Skills Categories

1. Main Theme: Making a Plan

Table 2: Students' Views about Planning

\begin{tabular}{ll}
\hline Subtheme & Student Code \\
\hline Daily Plan & S2,S10,S17,S18,S19,S20,S21,S22 \\
Weekly Plan & S1,S3,S6,S9,S11,S12,S13,S14,S15,S21,S23,S7 \\
Monthly Plan & S7 \\
Without Plan & S4,S5,S8,S16 \\
\hline
\end{tabular}


As Table 2 shows, 12 students reported that they made a weekly plan. 8 students stated that they made daily plans, only one student reportedly made a monthly plan and 4 students implied that they did not make a study plan. Examples of the students' responses are presented below:

S2 "I do not often make a study plan, but sometimes I make a plan. For instance, I will start with which course, etc."

S4 "I do not prepare a plan. When I want to study, I study."

S7 "I review a lot so, anyway, I always do a weekly plan. Only I have only one day free. I sometimes make a monthly plan as my parents say."

S8 "I do not make a study plan because I do not have the time. I cannot follow the plan, so I review the units; then I answer the questions."

S13 "I prepare a weekly plan. I prepare my weekly plan according to my school schedule."

S14 "I prepare a weekly plan. I prepare my plan according to my private school, which offers specialised courses."

S16 "I cannot prepare a plan because I cannot act in accordance with the plan. When I want to study, I study."

S18 "My study plan can change day by day."

S21 "I make a daily plan; sometimes I make a weekly plan. It can be changed."

2. Main Theme: Reviewing

Table 3: Students' Preferences for Reviewing

\begin{tabular}{ll}
\hline Subthemes & Student Code \\
\hline Reviewing as a whole & $\mathrm{S} 1, \mathrm{~S} 9, \mathrm{~S} 13, \mathrm{~S} 18, \mathrm{~S} 19, \mathrm{~S} 22$ \\
Reviewing by separating into smaller units & $\mathrm{S} 2, \mathrm{~S} 3, \mathrm{~S} 4, \mathrm{~S} 5, \mathrm{~S} 6, \mathrm{~S} 7, \mathrm{~S} 8, \mathrm{~S} 10, \mathrm{~S} 11, \mathrm{~S} 12, \mathrm{~S} 14, \mathrm{~S} 15, \mathrm{~S} 16, \mathrm{~S} 17$ \\
Reviewing both as a whole and by separating & $\mathrm{S} 20, \mathrm{~S} 21, \mathrm{~S} 23$ \\
into smaller units &
\end{tabular}

As Table 3 shows, 14 students said that they reviewed the units by separating them into smaller units. 6 students stated that they reviewed the units as a whole. 3 students said that they use both strategies. Examples of the students' responses are presented below:

S1 "Let's say, for instance, we study two units in a Turkish lesson. Firstly, I review these units as a whole, then I review the units by separating the parts."

S2 "I study the units by separating them into small sections because I understand better by separating one by one. I can remember a unit but I forget the other unit."

S3 "I divide. I make a test about the topic that I study so it is more permanent in my mind."

S7 "I divide. When I study units as a whole, I suppose that I cannot finish on time, so I separate the units."

S8 "I separate into small parts because I review as a whole. My mind relates with the first one, then I try to make a daily or hourly review. I answer the questions related to the topic. It remains better in my mind."

S11 "I divide chapter by chapter. I can become confused when I review the topics as a whole."

S13 "I review the units as a whole. I cannot comprehend completely when I separate the unit into small parts. For this reason I review as a whole."

S14 "I divide into small sections. I review the unit that I do not understand, then I study others."

S20 "I review as a whole because I read the unit as a whole to master the unit. However, if I do not understand, I separate the units. Both of them are possible."

S21 "I review as a whole because the topic that I review helps me to understand the other units that came before." 
3. Main Theme: Quietness of the Study Area

Table 4: Students' Views on the Quietness of the Study Area

\begin{tabular}{ll}
\hline Subthemes & Student Code \\
\hline Quietness is very important & $\mathrm{S} 3, \mathrm{~S} 7, \mathrm{~S} 8, \mathrm{~S} 14, \mathrm{~S} 17, \mathrm{~S} 19, \mathrm{~S} 21$ \\
Quietness is important & $\mathrm{S} 1, \mathrm{~S} 2, \mathrm{~S} 4, \mathrm{~S} 5, \mathrm{~S} 6, \mathrm{~S} 9, \mathrm{~S} 10, \mathrm{~S} 11, \mathrm{~S} 15, \mathrm{~S} 16, \mathrm{~S} 18, \mathrm{~S} 20, \mathrm{~S} 22, \mathrm{~S} 23$ \\
Quietness is not very important & $\mathrm{S} 13, \mathrm{~S} 12$ \\
\hline
\end{tabular}

As Table 4 shows, only two students said that quietness was not an important quality of their study environment. 14 students stated that quietness was important for their study environment, and 7 students implied that quietness was very important for their study environment. Therefore, most students believed that the room in which they study needs to be quiet for concentration and attention. Examples of the students' responses are presented below:

S1 "In fact, it is important but it can be a little noisy because when we take a test, it can be a little noisy."

S3 "It is very important because my attention is distracted in a noisy environment. When I study my lessons and my sister makes a little noise, it can be hard for me to not get angry."

S6 "It is important because it creates carelessness. It should be quiet."

S7 "It is very important because noise breaks concentration when studying."

S11 "It is important. I may get confused."

S12 "It is not so important, but if it is quiet, it is better."

S13 "If I am in a quiet environment, it is better. But, the family environment makes me more motivated. I cannot feel motivated when I am alone."

S14 "Yes, I have to read again and again in a noisy environment, for example when I answer the questions. But when the environment is quiet, I can understand easily."

4. Main Theme: Stress

Table 5: Students' Strategies for Managing Stressful Situations

\begin{tabular}{ll}
\hline Subthemes & Student Code \\
\hline Counting & $\mathrm{S} 1, \mathrm{~S} 5$ \\
Calming oneself down & $\mathrm{S} 2, \mathrm{~S} 10, \mathrm{~S} 13, \mathrm{~S} 20$ \\
Inspiring oneself (internal suggestion) & $\mathrm{S} 3, \mathrm{~S} 8$ \\
Sleeping & $\mathrm{S} 4, \mathrm{~S} 16$ \\
Resting & $\mathrm{S} 5$ \\
Playing brain games & $\mathrm{S} 6$ \\
Listening to music & $\mathrm{S} 7, \mathrm{~S} 12, \mathrm{~S} 15, \mathrm{~S} 10, \mathrm{~S} 21, \mathrm{~S} 22, \mathrm{~S} 23$ \\
Playing sports & $\mathrm{S} 9, \mathrm{~S} 12, \mathrm{~S} 13$ \\
Thinking & $\mathrm{S} 11, \mathrm{~S} 22$ \\
Wandering around (roaming) & $\mathrm{S} 13, \mathrm{~S} 18$ \\
Reading & $\mathrm{S} 14$ \\
Studying & $\mathrm{S} 15, \mathrm{~S} 19$ \\
Trying to forget & $\mathrm{S} 17$ \\
\hline
\end{tabular}

As Table 5 shows, students use a variety of strategies to manage their stress. 7 students said that they listen to music when they feel stressed. 4 students stated that they calmed themselves down, and 3 students said that they play sports. Examples of the students' responses are presented below:

S1 "When I'm stressed, I count backwards from 1 to 10 then take a deep breath. I relax."

S2 "When I'm stressed, I drink water. I calm down by myself."

S4 "I sleep when I'm stressed. After I sleep, I wash my face. I study my lesson."

S6 "I usually play a game. I try to play brain games."

S8 "When I'm stressed, I try to build self confidence in myself. I tell by myself, I can do it. I can do it for my family. I can accomplish it."

S9 "Studying lessons reduces stress. Sometimes I play football to reduce stress." 
S10 "At first, I calm down by myself."

S11 "When I'm stressed, I sit down and think in a high place."

S12 "I usually listen to music or do sports."

S18 "When I'm stressed, I go out and I take a breath."

S20 "When I'm stressed, I calm down by myself."

S21 "I listen to music."

S22 "When I get stressed, I listen to music or, if I am studying, I take a break for one or two minutes."

Table 6: Students' Views about the Impact of Stress on Learning

\begin{tabular}{ll}
\hline Subthemes & Student Code \\
\hline The stress level should be maintained appropriately. & $\mathrm{S} 1, \mathrm{~S} 3, \mathrm{~S} 4, \mathrm{~S} 7, \mathrm{~S} 8, \mathrm{~S} 12, \mathrm{~S} 16, \mathrm{~S} 18, \mathrm{~S} 22$ \\
Less stress promotes learning. & $\mathrm{S} 6, \mathrm{~S} 15, \mathrm{~S} 17, \mathrm{~S} 19, \mathrm{~S} 20, \mathrm{~S} 21$ \\
Stress does not promote learning. & $\mathrm{S} 2, \mathrm{~S} 5, \mathrm{~S} 9, \mathrm{~S} 10, \mathrm{~S} 11, \mathrm{~S} 13, \mathrm{~S} 14, \mathrm{~S} 23$ \\
\hline
\end{tabular}

As Table 6 shows, 9 students said that an average stress level was beneficial. 8 students stated that stress does not promote learning, and 6 students stated that less stress does promote learning. Examples of the students' opinions are presented below:

S1 "Stress should not be more or less. It should be at an average level so it does not affect the lesson in a bad way."

S3 "Too much stress is bad for recalling, so we should not feel too stressed. However, if we haven't any stress, we assume that we know all the units very well. Stress should be kept at an average level."

S6 "Yes, that is. If we haven't any stress, we cannot focus on the exam."

S8 "Stress affects learning in a negative way, but stress should be kept at an average level because if we do not have a certain level of stress, we cannot study."

S13 "When I get stressed, I can't answer the questions."

S18 "Being stressed doesn't promote better learning, but stress at an average level promotes it."

S20 "When we get stressed, we can make a lot of mistakes."

S22 "If we feel too much stress, we may make mistakes, but if we have stress at an average level, it can be beneficial. For example, we know that we should study, we should pass the exams, and we study according to these opinions."

S23 "We cannot understand anything. Stress has a negative impact."

5. Main Theme: Motivation

Table 7: Students' Strategies for Increasing Motivation

\begin{tabular}{ll}
\hline Subthemes & Student Code \\
\hline Changing situations (moving from a noisy environment to a quiet environment) & $\mathrm{S} 1$ \\
Solving easy questions before solving difficult questions & $\mathrm{S} 2$ \\
Positive internal suggestions about success & $\mathrm{S} 3, \mathrm{~S} 5, \mathrm{~S} 15, \mathrm{~S} 16$ \\
Remembering past successes & $\mathrm{S} 4, \mathrm{~S} 17$ \\
Reading a book & $\mathrm{S} 6$ \\
Family support & $\mathrm{S} 7, \mathrm{~S} 12$ \\
Using a notebook with attractive decoration & $\mathrm{S} 8$ \\
Tracking progress & $\mathrm{S} 9$ \\
Admiring the example of successful people & $\mathrm{S} 10, \mathrm{~S} 14$ \\
Reviewing & $\mathrm{S} 11, \mathrm{~S} 21, \mathrm{~S} 22, \mathrm{~S} 23$ \\
Reviewing the lesson units & $\mathrm{S} 13$ \\
Studying & $\mathrm{S} 18, \mathrm{~S} 20$ \\
Thinking of exams & $\mathrm{S} 19$ \\
\hline
\end{tabular}

Table 7 shows that students use a variety of strategies to increase their motivation. However, the most popular strategy was to use positive internal inspiration and reviewing. In addition, 1 student said that they motivate 
themselves by reviewing the lesson units. Examples of the students' responses are presented below:

S3 "For example, I think that my friends are hardworking. Why are they hardworking? Why I am not hardworking? I talk with myself and I try to pass so many tests. I want to get information from my friends about how they study. What is their study plan?"

S4 "I think about my past success. I learn from my past success."

S5 "I aim at an occupation (a profession)."

S6 "I motivate myself by playing games, solving puzzles and reading books."

S7 "If my parents support and motivate me, I want to study a lot. I am determined to study the lesson."

S8 "At first I make my notebook pleasing. I want to study it. For example, I write with colourful pens so my motivation increases."

S9 "For example, I have five right answers in the first exam, then I have six right answers in the second exam. I want to study."

S11 "I motivate myself by reviewing, reading and writing about the units."

S12 "By accepting my parent's opinions and their positive answers. They motivate me."

S14 "I look to the example of someone who studies, then I try to study. For example, I study when my uncle studies his lessons."

S16 "For example when I study a lesson, I tell myself I should be successful. You must accomplish your dreams."

S20 "I increase my motivation by studying."

S22 "I take tests on the units that I like. I study them a lot."

\section{Discussion}

In this study, several study skills categories were considered. Students who had high academic grades stated reviewing, making a plan, a quiet study environment, stress-free and motivation are important factors for successful studying. They gave diverse reasons for using a variety of reviewing strategies to study their lessons. These data and data analysis help and serves as a guide for who had no high academic grades. For instance, one of the students said he separates the units or topics when reviewed as whole because he believes that he does not have enough time to cover all of the material. Another student said that he uses a similar reviewing technique when he reviews the subjects as whole because in order to understand the subject matter. Some students implied that they use both types of reviewing strategies. Most students prefer a quite room or study area because a noisy environment hinders concentration and attention while only two students felt that the quietness of the study area is not very important. "Studying in a quiet place" is recommended, but some students have different preferences for quietness, sound, noise, etc. In addition, it has been shown that music with low sounds can calm the neural system (Erden \& Altun, 2006). Students implied that they have different attitudes when they feel stressed. Most of the students listen to music when they feel stressed. Students' strategies for self-motivation varied widely; and the other most of students said that a low level of stress does not promote learning while some students said that low stress does promote learning. However, some students stated that they instil in themselves a positive self-attitude; some students reported that they motivate themselves by reviewing the units and topics. The results show that students who have high academic grades appear to apply the study skills described in the literature when they study their lessons. In addition, most students' perspectives in this study is related to the study skills categories support by Pemble (2004), his PhD thesis titled "An Exploration of Student Differences Related to Study Skills and Student School Performance"; studied in a rural school with 289 students and evaluated the overall learning skills. The students were divided into four groups and compared. The groups include General Education, Language and Literature, Special Education, and students with low notes. Study Skills were evaluated with study skills inventory covering 35 questions. The results obtained from study skills inventory was evaluated according to three factors. The scores were based on motivation and endurance strategies, the use of study skills and homework. Descriptive and inferential statistics were used in this study. Students are divided into two groups, high and low notes as average students. According to results of One-Way ANOVA, the study skills inventory evaluations; there are significant differences between the student groups' average scores. Kutlu and Korkmaz (2013) expressed again studying skills' effects on second level primary school students' academic success. The main purpose of this research is to determine the effects of study skills on academic success of the students and retention of the knowledge. This research was designed in true experimental model. The data which was 
used in this research was collected by the multiple choice test which was developed by the researchers. The treatment and control group of this research consisted of forty students who were eight grades between the ages 13-15, in the school year 2009-2010 in a rural State Primary School which is medium socio-economic level in Arnavutköy - İstanbul. According to the result of the pre-tests and post-tests, between the treatment and control groups, there were not significant differences. Whereas the results of the retention test showed significant differences. Smith, Teske and Gossmeyer (2000) suggested that parental involvement is a key factor in determining student academic achievement in their research. Their study described a program for improving students' study skills aimed at improving academic performances. The targeted population consisted of students in two public high schools and one parochial grade school in a medium-sized metropolitan area located in central Illinois. The lack of study skills by students at all levels had been demonstrated through surveys, teacher observations, professional writings, and poor student achievement. Analysis of probable cause data revealed that many students failed to possess adequate study skills which included note taking, test preparation, time management, and organizational skills. Baseline data demonstrated that students were lacking in the aforementioned skills. Through intervention, the researchers hoped to enhance student academic performance. Although most of the students did not indicate significant improvement, the students gained knowledge about various study skills and when best to implement them. Based on the results of this research, it is considered that study skills categories bring positive impact on students' academic achievement. The views of students who had high academic grade, including students' study skills categories indicate a positive effect on academic achievement in this qualitative research. Educators should continue to support the students for awareness of the study skills categories. In addition, parents need to contribute to their children's learning process; since knowing how helpful they are to their children's academic success, may help children to be more successful.

\section{References}

Açıkgöz, K. Ü. (2005). Etkili öğrenme ve ögretme (6th ed.). İzmir: Education World. Alkış Publications; 2005.

Best J. W., \& Kahn J. V. (2006). Research in education (10th ed.). Boston: Pearson Education, Inc.

Büyüköztürk, Ş., Çakmak, Kıç, E., Akgün, Ö. E., Karadeniz, Ş., \& Demirel, F. (2008). Bilimsel araştırma yöntemleri. Ankara: Pegem Yayınevi.

Cohen, L., Manion, L., \& Morrison K. (2007). Research methods in education (6th ed.). New York, NY: Taylor and Francis Group.

Cottrell, S. (2003). The study skills handbook (2nd. Ed.). New York, NY: Palgrave Macmillan Ltd.

Driscoll, M. P. (2005). Psychology of learning for instruction (3rd ed.). Boston: Pearson Education, Inc.

Ekmekçi, Ö. (1994). Ways of attaining study skills. İstanbul: Literatür Publication.

Erden, M., \& Altun, S. (2006). Öğrenme stilleri. İstanbul: Morpa Publications.

Fetterman, D. M. (1988). Qualitative approaches to evaluation in education. The silent scientific revolution. New York, NY: Praeger

Fosnot, (2005). Constructivism (2nd ed.). New York, NY and London: Teachers College Press Columbia University.

Fraenkel, J. R., \& Wallen, N. E. (1993). How to design and evaluate research in education (2nd ed.). Singopore: McGraw-Hill.

Fraenkel, J. R., \& Wallen, N. E. (2006). How to design and evaluate research in education (6th ed.). New York, NY: McGraw-Hill.

Fraenkel, R. M., \& Devers, K. J. (2000). Study design in qualitative research-1: Developing questions and assessing resource needs. Education for Health, 13(2), 251-261. http://dx.doi.org/10.1080/13576280050074534

Frender, G. (2003). Learning to learn: Strengthening study skills \& brain power (Rev. ed.). Nashville, Tennessee: Incentive Publications, Inc.

Glesne, C. (2011). Becoming qualitative researchers (4th ed.). Boston: Pearson Education.

Kutlu, M.O., \& Korkmaz, Ş. (2013). Studying skills' effects on second level primary school students' academic success. Elektronik Sosyal Bilimler Dergisi, 12(47), 1-10.

Kutlu, O., \& Bozkurt M. C. (2007). Okulda ve sinavlarda adım adım başarı. Konya: Çizgi Bookstore.

Luckie, W. R., \& Smethurst W. (1998). Study power, study skills to improve your learning and your grades. 
Cambridge, Massachuetts: Brookline Boks.

Mundsack, A., Deese, J., \& Deese, E. K. (2003). How to study and other skills for success in college (5th ed.). United States of America (USA): McGraw-Hill.

Nelson, A. P., \& Gilbert, S. (2005). Achieving optimal memory (1st ed.). United States of America (USA): McGraw-Hill.

Patton, M. Q. (1990). Qualitative evaluation and research methods (2nd ed.). London: Sage Pub.

Pauk, W. (2001). How to study in college (7th ed.). Boston-New York: Houghton Mifflin Company.

Pemble, R. (2004). An exploration of student differences related to study skills and student school performance(Doctoral dissertation, Seattle Pacific University, 2004). Retrieved December 1, 2009, from http://proquest.umi.com/pqdweb?index=116\&did=790249631\&SrchMode=1\&sid=2Fmt=\&Vnst=PROD\&VTyp $\mathrm{e}=\mathrm{PQD} \& \mathrm{RQT}=309 \& \mathrm{Name}=\mathrm{PQ}$

Philips, D. C., \& Soltis, J. F. (1991). Perspectives on learning. New York, NY: Teachers College, Columbia University.

Robinson, A. (1993). What smart students know: Maximum grades. Optimum learning. Minumum time. New York, NY: Three Rivers Press.

Schmeck, R. R. (1988). Learning strategies and learning styles. New York, NY: London: Plenum Press. http://dx.doi.org/10.1007/978-1-4899-2118-5

Senemoğlu, N. (2005). Gelişim öğrenme ve öğretim. Ankara: Gazi Publishing House.

Smith, M., Teske, R., \& Gossmeyer, M. (2000). Improving student achievement through the enhancement of study skills. Research project. Illionois, Chicago: Saint Xavier University \& SkyLight Professional Development.

Strauss, A., \& Corbin, J. (1998). Basics of qualitative research: Techniques and procedures for developinggrounded theory (2nd ed.). Thousand Oaks, California, CA: Sage.

VanderStoep, S. W., \& Pintrich, P. R. (2003). Learning to learn: The skill and will of college success. New Jersey, NJ: Pearson Education, Inc.

Wong, L. (2006). Essential study skills (5th ed.). Boston, New York, NY: Houghton Mifflin Company.

Yıldırım, A., \& Şimşek, H. (2008). Sosyal bilimlerde nitel araştırma yöntemleri. (6th ed.). Ankara: Seçkin Publication. 